\title{
O Programa de Residência em Medicina de Família e Comunidade do município de Florianópolis
}

The Family and Community Medicine Residency Programme of the municipality of Florianópolis

\section{Programa de Residencia en Medicina Familiar y Comunitaria del municipio de Florianópolis}

Nulvio Lermen Junior. Secretaria Municipal de Saúde de Florianópolis (SMS-PMF). Florianópolis, SC, Brasil. nulvio@hotmail.com (Autor correspondente)

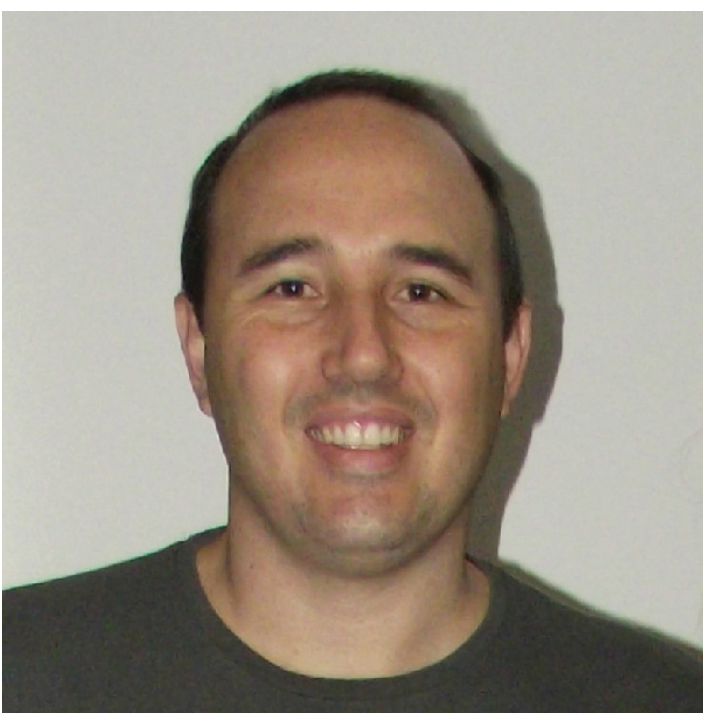

"Como fator preponderante para a manutenção da qualidade das equipes de saúde da familia, o municipio há 10 anos decidiu pagar diferenciadamente quem é especialista em Medicina de Familia e Comunidade e tem realizado rotineiramente concursos públicos com este pré-requisito para preencher as vagas que surgem em nossa rede de APS."
Nulvio Lermen Junior é médico de familia e comunidade (MFC) e secretário adjunto da Secretaria Municipal de Saúde de Florianópolis-SC. Nesta entrevista, Dr. Nulvio Lermen Junior discorre sobre como está organizada a Atenção Primária à Saúde no município de Florianópolis e também sobre como ocorreu a implementaçáo do Programa de Residência em Medicina de Família e Comunidade (PRMFC) vinculado à SMS de Florianópolis, que oferece, atualmente, 16 vagas anuais. A RBMFC entrevistou o Dr. Nulvio Lermen Junior via e-mail em 13/08/2014, e a principal temática abordada foi a formação em Medicina de Família e Comunidade e a importância dessa especialidade médica para a expansão e qualificação da Atenção Primária à Saúde (APS) no município. 
RBMFC: De que forma o município de Florianópolis tem investido na Atenção Primária à Saúde (APS) e na Estratégia Saúde da Familia (ESF)?

Nulvio Lermen Junior: Florianópolis historicamente tem se destacado pelo investimento na APS, estando sempre entre as capitais com maior cobertura de Saúde da Família (SF) do Brasil. Apesar de termos todo o território do município coberto pela ESF, temos dado continuidade à expansão do número de equipes de SF, pois há a intenção de paulatinamente aproximarmos a população sob responsabilidade de cada equipe ao padrão internacional, que é de 2.000 a 2.500 pessoas por ESF. Além disso, o município vem investindo na qualificação das equipes já existentes através de um processo de educação continuada para seus servidores e do investimento na formação profissional com a integração ensino-serviço em parceria com a UFSC na graduação. Outro investimento que merece destaque foi a criação de uma residência própria em MFC com 16 vagas anuais.

Como fator preponderante para a manutenção da qualidade das equipes de SF, o município há 10 anos decidiu pagar diferenciadamente quem é especialista em Medicina de Família e Comunidade e tem realizado rotineiramente concursos públicos com este pré-requisito para preencher as vagas que surgem em nossa rede de APS.

RBMFC: Quais os dados atualizados da cobertura da ESF em Florianópolis e quais os principais desafios a serem enfrentados para a melhoria da qualidade dos serviços oferecidos para a consolidação da APS/ESF?

Nulvio Lermen Junior: Apesar dos dados do Ministério informarem uma cobertura de 95\%, o município tem todo o seu território coberto pela ESF. A intenção é ultrapassar os 100\% de cobertura mesmo na estimativa do Ministério nos próximos meses.

Os principais desafios, como já informado, são diminuir a proporção população/equipes de SF e qualificar a rede de serviços. Para isso, além das estratégias anteriormente expostas, pretendemos valorizar os profissionais com a revisão da política de pagamento por desempenho, priorizando fatores que fortaleçam os atributos principais da APS (Acesso, Longitudinalidade, Integralidade e Coordenação) e utilizando as potencialidades desses mesmos profissionais na elaboração de materiais de apoio às equipes, como linhas-guias e protocolos de ação.

RBMFC: Quais os principais motivos que levaram o município de Florianópolis a implementar um Programa de Residência em Medicina de Familia e Comunidade (PRMFC) pela SMS?

Nulvio Lermen Junior: A formação de recursos humanos para a saúde é uma responsabilidade compartilhada entre todos os entes federativos que compóem o SUS. Se quisermos ter profissionais com perfil para atuação no sistema público, nada mais natural do que formá-los dentro desse cenário, e isso é especialmente importante quando se trata da APS. Transferir (ou deixar) essa responsabilidade exclusivamente com as universidades é um erro que pode repercurtir posteriormente no serviço. Sendo assim, atuar na formação desses profissionais é uma necessidade e uma decisão estratégica para qualquer município de médio e grande porte que queira contar com uma APS qualificada.

RBMFC: Quais os desafios e as estratégias adotadas para a implementação do PRMFC?

Nulvio Lermen Junior: Florianópolis tem uma característica diferenciada da maioria dos municípios do país, pois conta com a grande maioria das suas equipes compostas por médicos especialistas em MFC. Portanto, o grande problema que outros programas enfrentam em encontrar preceptores qualificados não aconteceu por aqui. O grande desafio, por mais estranho que possa parecer, foi encontrar espaço nas unidades para a atuação dos residentes.

O município conta com uma rede de 50 Unidades Básicas de Saúde, sendo quase a totalidade com estrutura física e de equipamentos adequada, completamente informatizada e com uma rede de informaçóes interligada que cobre também as unidades de pronto atendimento e as policlínicas. Apesar disso, com o crescimento do número de equipes, a estruturação de outros serviços na APS, como os NASF, e a inserçáo maciça de alunos de graduaçáo na APS, praticamente todos os espaços físicos dentro das unidades está ocupado o tempo inteiro, em especial os consultórios. Sendo assim, o município teve de reformar boa parte das unidades para prepará-las para a entrada dos residentes, resultando em um investimento de mais de 250 mil reais bancados com recursos exclusivamente municipais.

Além disso, o município teve de adequar a sua legislação, criando uma lei específica que permitisse pagar a complementação de bolsa para os residentes, assim como efetivar o repasse de uma gratificação específica para a preceptoria aos MFC que acompanham esses residentes. 


\section{RBMFC: Como está organizado o PRMFC?}

Nulvio Lermen Junior: O programa tem 16 vagas anuais de R1 distribuídas em unidades de todas as regióes do município. Pela característica única de abundância de preceptores qualificados, tomamos a decisão pela proporção de um preceptor para cada residente, sendo que o preceptor e o residente compartilham a área (e os pacientes) da equipe de SF à qual o preceptor está vinculado.

Para o próximo ano, esperamos contar com uma residência em enfermagem coordenada com a residência médica, na qual ambos os residentes deverâo formar uma subequipe de SF da equipe a que seus preceptores pertencem, proporcionando assim uma experiência ainda mais próxima da realidade que irão enfrentar ao fim de seu processo de formação.

RBMFC: De que forma o PRMFC pode ser sustentável para o município?

Nulvio Lermen Junior: O PRMFC, se adequadamente organizado e planejado, pode ter um balanço positivo no que diz respeito aos recursos financeiros que podem ser captados junto ao MS em relação aos seus gastos, mas é essencial frisar que isso nunca deve ser o foco da implementação do programa. Caso contrário, a formação corre sério risco de ser preterida em relação à captação de recursos.

Explicando sobre a sustentabilidade financeira: com o advento da Portaria 1248 de 28 de junho de 2013, que destina recursos para instituiçôes que implementam PRM em especialidades estratégicas para os SUS, passou a haver um certo equilíbrio entre os gastos de um PRM e os repasses de recursos do MS para a manutenção desses programas, somando-se a isso ainda a abertura para que os residentes em MFC façam parte de equipes de SF em conformidade com a Portaria 3147 de 2012, o que potencializa em muito a possibilidade de captação de recursos por parte dos municípios.

RBMFC: Que estratégias o município tem adotado para atrair candidatos ao PRMFC e depois manter os residentes egressos no municipio?

Nulvio Lermen Junior: Primeiro, quanto a atrair os residentes, há uma tradição de inserção precoce dos alunos de graduação na rede de APS do município, sendo que isso ocorre há mais de uma década, com um histórico bastante positivo, tanto para a universidade quanto para o município. A inserção dos alunos em serviços de APS de qualidade com preceptores bem formados é certamente o primeiro passo para a atraçáo dos potenciais candidatos. Além disso, passamos a lançar mão de estratégias que também são adotadas por outros PRMFC pelo país, como o pagamento de uma complementação de bolsa para os residentes, a realização de concursos complementares quando da não ocupação de todas as vagas em um primeiro concurso e a divulgaçáo maciça sobre o programa junto aos egressos dos cursos de medicina do estado.

Para a manutenção dos egressos, o município tem realizado regularmente concursos públicos buscando absorver todos os egressos, não só dos programas do município, mas também visando a atrair egressos de outros programas. Podemos afirmar categoricamente que nenhum egresso de nosso programa deixa de ser absorvido em nossa rede, a não ser que não queira, mesmo porque seria uma contradição investir na formação e deixar de absorver esses profissionais.

"Nenhum egresso de nosso programa deixa de ser absorvido em nossa rede, a não ser que não queira, mesmo porque seria uma contradição investir na formação e deixar de absorver esses profissionais."

\section{RBMFC: Como está organizada a estrutura do PRMFC?}

Nulvio Lermen Junior: A estrutura obedece a todos os preceitos constantes nas normativas da Comissão Nacional de Residência Médica. Quanto à proporção preceptor/residente, conforme informado anteriormente, optamos por uma relação de um para um, sendo que o residente, para além dos serviços de APS do município, tem a oportunidade de passar por estágios em nossos serviços de urgência e nas policlínicas municipais.

RBMFC: Existe parceria com instituição de ensino superior que está apoiando o programa de residência, visto que Florianópolis possui pelo menos uma Universidade Federal que oferece graduação em medicina?

Nulvio Lermen Junior: Há um amplo histórico de cooperação entre a Secretaria Municipal de Saúde e a Universidade Federal de Santa Catarina no que diz respeito à formação na área da saúde e em especial na medicina. Essa cooperação vai desde a graduação, onde temos mais de 600 alunos de medicina inseridos em nossos serviços da APS, e se estende até a residência, onde há o compartilhamento de espaços de formaçáo e de atividades educativas entre as duas instituiçóes. 
RBMFC: Dada a recente expansão de programas de residência em MFC vinculadas às Secretarias Municipais de Saúde, qual conselho você daria para gestores municipais interessados em implantar um programa de residência?

Nulvio Lermen Junior: A formação de recursos humanos para o SUS é uma necessidade e uma decisão estratégica para todos os municípios de médio e grande porte no Brasil. Nesse sentido, o meu conselho é que cumpram o seu papel de formadores dentro desse sistema, pois a formação deve ser cada vez mais próxima da realidade, e quem sabe da prática é quem a executa.

Sobre o entrevistado: Graduado em Medicina pela Universidade Federal de Santa Catarina (UFSC). Mestre em Políticas e Gestão de Saúde pela Universidade de Bolonha - Itália. Médico concursado pela Prefeitura Municipal de Florianópolis. Médico de Família e Comunidade titulado pela Sociedade Brasileira de Medicina de Família e Comunidade em 2004. Médico do Programa de Interiorização do Trabalho em Saúde-PITS no estado de Pernambuco entre 2001 e 2002. Coordenador de Regional de Saúde, Assessor Chefe de Atenção à Saúde do Município de Florianópolis entre 2005 e 2007. Coordenador de Gestão da Atençấo Básica do Ministério da Saúde entre 2007 e 2011. Coordenador de Saúde da Família do Município do Rio de Janeiro e Coordenador da Residência em Medicina de Família e Comunidade da Secretaria Municipal de Saúde do Rio de Janeiro entre 2011 e 2013. Presidente da Sociedade Brasileira de Medicina de Família e Comunidade no biênio 2012-2014. Secretário Adjunto de Saúde do Município de Florianópolis desde 2013. Diretor de Titulação da Sociedade Brasileira de Medicina de Família e Comunidade para o biênio 2014-2016. Tem experiência na área de Saúde Coletiva, com ênfase em Atenção Primária à Saúde.

Entrevista concedida via e-mail em 13/08/2014.

Edição de texto: Michael Schmidt Duncan. 